\title{
Nonlinear Loading Effects in Oxide-filled Polyester Nanocomposites Observed by IR-spectroscopy and Lifetime Positron Spectroscopy
}

\author{
Borys M.Gorelov ${ }^{1}$, Oleksiy I. Polovina ${ }^{2}$, Alla M. Gorb ${ }^{2, *}$, Marek Kostrzewa ${ }^{3}$, Adam Ingram³ \\ ${ }^{1}$ Chuiko Institute of Surface Chemistry, National Academy of Sciences of Ukraine, 03164, Kyiv, Ukraine \\ ${ }^{2}$ Department of Physics, Taras Shevchenko Kyiv National University, 03127, Kyiv, Ukraine \\ ${ }^{3}$ Department of Physics, Opole University of Technology, 45370, Opole, Poland
}

Copyright $\mathrm{C} 2018$ by authors, all rights reserved. Authors agree that this article remains permanently open access under the terms of the Creative Commons Attribution License 4.0 International License

\begin{abstract}
Impact of nanosized oxide particles of titania (rutile) $\left(\mathrm{TiO}_{2}\right)$ and silica-titania fumed compound on physical properties related to inner structure of a styrene-cross-linked polyester resin have been experimentally studied. The IR-spectroscopy and the positron annihilation lifetime spectroscopy (PAL) were used to study the electronic polarizability of interatomic bonds and the positron annihilation processes with increasing the filler loading. All the nanocomposites show unmonotonous variations in the IR-absorption lines and the positron annihilation parameters. Three lifetime components, namely $\tau_{1}, \tau_{2}$, and $\tau_{3}$ with intensities $\mathrm{I}_{1}, \mathrm{I}_{2}$, and $\mathrm{I}_{3}$ have been determined. The lifetime loading dependences exhibit non-monotonous lowering within the low loading range $\left(\mathrm{C}_{\mathrm{m}} \leq 5 \%\right)$ with the minima values at $\mathrm{C}_{\mathrm{m}} \sim 1.5 \%$ for the unfilled resin and the nanocomposites. The free-volume portion $\mathrm{f}_{\mathrm{v}}$ (in \%) in a polymer matrix decreases droningly for the nanocomposites with STO-particles upon loading while for the $\mathrm{TiO}_{2}$-nanocomposites it increases non-monotonously. The parameters describing the supramolecular structure of the nanocomposites have been calculated using the fractal approach. Some correlations between loading-dependent PAL-properties and underlying alterations in the resin's supramolecular structure have been discussed.
\end{abstract}

Keywords Polyester Resin, Titanium Oxides, Nanocomposite, Positron Annihilation, Positronium, IR Absorption, Fractal Analysis, Supramolecular Structure

\section{Introduction}

In recent years, nanosized oxides such as $\mathrm{SiO}_{2}$ [1-6], $\mathrm{TiO}_{2}$ [7-10], and silica-titania (STO) fumed compound [10] are being intensively employed as fillers to improve electric, mechanic, or thermal properties of various polymers. Thermosetting polymers with a three-dimensional network structure are more useful in practical applications than thermoplastics because they are harder, more chemically inert and have better mechanical strength and heat resistance due to the high degree of crosslinking between polymeric chains [11]. The unsaturated polyester resin (UPR) used in the present work is a typical example of a good-performing network polymer.

A promising feature of oxide-filled polyester nanocomposites (PNCs) is a possibility of tailoring their parameters by varying filler's loading, particle's size, dielectric permittivity, and number of active surface sites [12-16] because these are the factors which influence on particle-polymer interactions [17]. However, the data related to PNCs show that there is only a little progress in our understanding of particle-macromolecule interaction mechanisms and structure-property relations. Therefore, the question of how to optimize tailoring the physical properties of PNCs for specific/customer needs by varying the above-mentioned filler's parameters still remains one of the most important challenges for applied polymer sciences.

Filling of amorphous glasslike polymers (in particular, UPR) leads to restructuring of polyester and styrene chains, changing a number of unfixed fragments of macromolecule, appearance of double layers with internal electric fields. It has recently been shown that filling the UPR with either titania or silica-titania fumed oxide results in breaking the styrene cross-links and increasing a number of the unlinked moieties [10]. The dependencies of the physical parameters on filler content are characterized by a non-monotonic pattern which is clearly revealed at low filler content. It may be supposed, that the structural adjustment in the polyester nanocomposites is accompanied with electron density distribution among polymer chains, defects, and atomic groups varying their polarizability and dipole moments. 
It has early been shown known that epoxy resins [18-23] and other thermosetting polymers [24, 25] can exhibit structural inhomogeneities in nanoscale arising either from decreased miscibility of initial components during a curing reaction or from curing involving other reaction mechanisms. Recent studies which have been made by using the atomic force microscope at fracture interfaces [26-30], IR-spectroscopy [26, 27, 29, 30], and differential scanning microscopy $[26,27]$ confirmed that epoxy-amine resins possess a heterogeneous, submicrometer nodular structure. Multiple researchers have proposed that these nodular structures are composed of regions of relatively higher cross-linking surrounded by an interstitial phase of relatively lower cross-link density [21, 23, 26, 28]. Therefore, it is reasonable to assume that unsaturated polyester resins, being thermosetting polymers, also possess inhomogeneous, supramolecular structure. Hereafter, we will use the term "cluster structure", considering tightly packed nodules as clusters and loosely packed nodules as disordered areas. Thus, when speaking about a supramolecular structure of random-particulate polymer nanocomposites one should keep on mind that the structure includes several different locally-arranged areas, namely the nanoparticles themselves, the interfacial regions surrounding the nanoparticles, and the polymeric clusters and disordered areas.

Therefore, it may be suggested that the rearrangement of polyester chains, styrene cross-links, and unlinked atomic groups of polyester and styrene chains within 3D-molecular network induces by nanoparticles will be accompanied by a change in electronic density on atomic, molecular and supramolecular structural scales.

Thus, the present study was undertaken to investigate alterations in the electronic structure of styrene cross-linked unsaturated polyester resin caused by nanosized titanium dioxide and silica-titania fumed oxide with relatively low number of active surface sites. For this purpose, the dynamics of IR absorption and the annihilation of positrons processes induced by filler load changes were monitored. In addition, the parameters describing the supramolecular structure of nanocomposites were evaluated using the fractal method.

\section{Materials and Methods}

\subsection{Materials}

A commercially available orthophtalic styrene cross-linked unsaturated polyester resin "Polymal 1094 AWTP-1" (Poland) was used as the UPR matrix. It is a thermosetting polymer of a 3D-network molecular structure [31].

Chemical structure of a typical orthophtalic unsaturated polyester resin can be found elsewhere [32]. It is composed of the polyester macromolecular chains and the styrene cross-links bridging two polyester chains together. The number of styrene molecules in the link may vary, mainly, from 1 to 3 [33]. Essentially is that not every elementary polyester unit is linked and the unlinked units are randomly distributed along a macromolecular polyester chain.

Titanium dioxide of the rutile form (Ukraine) and the silica-titania fumed oxide (TAS-40, Ukraine) hereinafter referred to as STO, were nanofillers. Oxides differ from each other by the number of active surface sites and the nature of their interaction with resin macromolecules.

The titania particles were characterized with averaged diameter $2 \mathrm{R}_{\mathrm{f}} \sim 25 \mathrm{~nm}$ and specific surface area $\mathrm{S}_{\mathrm{f}} \sim 10$ $\mathrm{m}^{2} \mathrm{~g}^{-1}$, whereas STO-particles were of $2 \mathrm{R}_{\mathrm{F}} \sim 40 \mathrm{~nm}$ and of $\mathrm{S}_{\mathrm{f}} \sim 40 \mathrm{~m}^{2} \mathrm{~g}^{-1}$. For both the fillers their mass loading $\mathrm{C}_{\mathrm{m}}$ in the composites varied as $0.5,1.5,3.0$, and $5.0 \%$.

The values of $\mathrm{S}_{\mathrm{f}}$ were determined by measuring the amount of physically adsorbed nitrogen gas from adsorption-desorption isotherms according to the standard Brunauer, Emmett and Teller (BET) method [34] with Autosorb Station 3 of "Quantachrome Instruments Company" (USA).

The active surface sites (ASSs) of titania surface are TiO (oxygen vacancies with the $\mathrm{Ti}^{3+}$ ions) as either $\mathrm{Ti} \rightarrow \mathrm{O}$ bonds or $\mathrm{O} \rightarrow \mathrm{Ti}$ bonds [3] and $\mathrm{TiOH}$ [35]. There are the same centers on the surface of STO, and also SiO, silanol groups $\mathrm{Si}-\mathrm{OH}$, siloxane groups $\mathrm{Si}-\mathrm{O}-\mathrm{Si}$ and $\mathrm{Ti}-\mathrm{O}-\mathrm{Si}$ bridges [36]. In general, titania particles contain a small number of active surface areas compared to STO.

Figure 1 compares IR-absorption spectra of silica-titania fumed oxide (the curve "1"), and titanium dioxide (rutile, the curve "2"). One can see that the spectrum of STO (the curve "1") contains the wide bands of free OH-groups (centered at $3750 \mathrm{~cm}^{-1}$ ) and of absorption centers of $\{\mathrm{Ti}-\mathrm{O}(\mathrm{H})-\mathrm{Ti}\}$ (centered at $1454 \mathrm{~cm}^{-1}$ ). Neither such ASSs nor other ones are not present on the surface of rutile. Thus it is less active catalytically as compared to STO.

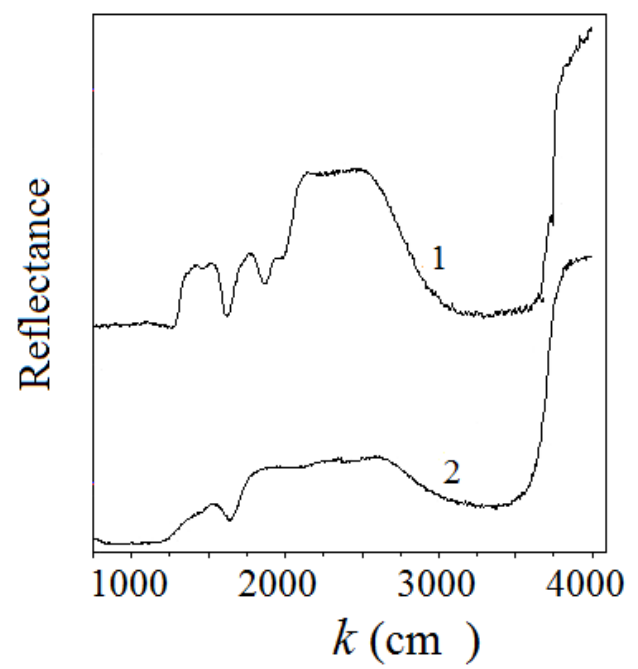

Figure 1. IR-reflection spectra of filling nanoparticles -silica-titania fumed oxide (the curve " 1 "), and titanium dioxide (rutile, the curve "2")

To remove organic contaminants and adsorbed water 
from the surface, the oxide powders underwent thermal treatment at about $400 \mathrm{~K}$ during 1.5 hours in air before preparing the nanocomposites.

Nanocomposites were prepared from UPR-solutions mixed by hand with filler in homogeneous mixtures. The polymerization of the mixtures occurred at a room temperature during 72 hours.

\subsection{Experimental Methods and Theoretical Tools}

Experimental studies were performed using IR-spectroscopy and the positron annihilation lifetime spectroscopy (PALS). The first technique enables to evaluate a deformation polarizability of atomic bonds at atomic level while the second is sensitive at molecular scale (what can be considered as free volume in which positrons are trapped or positronium is formed).

Infrared diffusion reflection spectra were detected at room temperature with the Thermo Nicolet NEXUS FT-IR spectro-photometer in the range of $400-4000 \mathrm{~cm}^{-1}$ with the resolution of $2 \mathrm{~cm}^{-1}$.

A fast timing configuration of the "Ortec" positron lifetime system was used to obtain the positron annihilation spectra (see [6] for details). The analysis of the positron annihilation spectra was performed by using the LT-programm [37] with no constrains imposed on the lifetime components.

Finally, some parameters of supramolecular structure have been estimated by using the fractal approach described in $[38,39]$.

\section{Results and Discussion}

\subsection{The Positron Annihilation Lifetime Spectroscopy}

It has been established by using the PAL-technique that three channels of positron annihilation of with intensities $I_{1}$, $\mathrm{I}_{2}, \mathrm{I}_{3}$ and the corresponding lifetimes $\tau_{1}, \tau_{2}$, and $\tau_{3}$ take place in both the unfilled resin and their nanocomposites. The lifetimes correspond to delocalized positrons annihilating directly from defect-free bulk states and from spin singlet para-positronium $\left(\tau_{1}\right)$ and to the annihilation of positrons trapped by the structural defects $\left(\tau_{2}\right)$, and to the pick-off annihilation of the ortho-positronium atoms captured by extended defects with lowered electron density $\left(\tau_{3}\right)$. For the unfilled resin the lifetimes are: $\tau_{1}=204.1 \mathrm{ps,}$ $\tau_{2}=471 \mathrm{ps}, \tau_{3}=1914 \mathrm{ps}$.

When introducing nanoparticle filler, the lifetimes of the positrons are similar and are characterized by non-monotonic decreases with increasing particle concentration $\left(\mathrm{C}_{\mathrm{m}}\right)$ reaching the minimum values when the $\mathrm{TiO}_{2}$ and STO content are equal to $1.5 \%$ (see Fig. 2).

Being corrected by a contribution from quasi-free-positron annihilation, $\mathrm{I}_{1}\left(\mathrm{C}_{\mathrm{m}}\right)$ and $\tau_{1}\left(\mathrm{C}_{\mathrm{m}}\right)$ should be replaced by $\mathrm{I}_{10}\left(\mathrm{C}_{\mathrm{m}}\right)$ and $\tau_{10}\left(\mathrm{C}_{\mathrm{m}}\right)$, respectively [39]

$$
\begin{gathered}
I_{10}=I_{1}-4 I_{3}, \\
\tau_{10}=\tau_{1}+\frac{\tau_{1}-\tau_{2}}{1+\lambda_{0}^{S} \tau_{3}} \cdot \frac{I_{3}}{I_{10}},
\end{gathered}
$$

where $\lambda_{0}{ }^{\mathrm{S}}=8 \times 10^{9} \mathrm{~s}^{-1}$ is annihilation rate for the para-positronium atom in vacuum. Numerical calculations by using "(1)" and "(2)" show the contribution from quasi-free-positronium annihilation into $I_{1}$ is equal $17-19 \%$ over the entire loading range and about 3\% into $\tau_{1}$. Therefore, the loading dependences of both $\mathrm{I}_{10}\left(\mathrm{C}_{\mathrm{m}}\right)$ and $\tau_{10}\left(\mathrm{C}_{\mathrm{m}}\right)$ remain very close to those of $\mathrm{I}_{1}\left(\mathrm{C}_{\mathrm{m}}\right)$ and $\tau_{1}\left(\mathrm{C}_{\mathrm{m}}\right)$. By other words, the quasi-free-positronium annihilation impact slightly on the annihilation process of free positrons.

Further, taking into account that the annihilation times $\tau_{\mathrm{i}}$ are inversely proportional to the related electron densities we may write

$$
\tau_{1} \sim 1 / n_{e}, \quad \tau_{2} \sim 1 / \rho_{+}, \tau_{3} \sim 1 / \rho_{P S},
$$

where $n_{e}$ is roughly equal to the average electron density within the polymer chains, and $\rho_{+}$and $\rho_{\mathrm{Ps}}$ are electron charge densities on walls of defects trapping positrons and positronium, respectively. Thus, loading dependences of $\tau_{\mathrm{i}}$ show variations in electron charge distribution within the annihilation volume of the nanocomposites with increasing the loading. Since the loading dependences of all annihilation times are similar to each other it may be assumed that chain-rearrangement mechanisms underlying increasing $n_{e}, \rho_{+}$, and $\rho_{P s}$ for low loadings $\left(C_{m} \leq 1.5 \%\right)$ are the same.

For both nanocomposites, the dependence of quasi-free positron annihilation (or, in other words, the probability of positron annihilation from a given state) on the doping level is characterized by the occurrence of $\mathrm{I}_{1}$ minimum that correspond to the maximum of $n_{e}$ values. This course of dependence $I_{1}$ on $C_{m}$ appears to be related to the reduction of electron density, in areas where annihilation occurs within the first component, for low filler concentrations when $0.5<\mathrm{C}_{\mathrm{m}}<3 \%$.

On the other hand, the growth of electron density $\left(\mathrm{n}_{\mathrm{e}}\right)$ in polymer chains is accompanied by an increase in both electron density on the walls of positron-trapping defects $\left(\rho_{+}\right)$and the value of $I_{2}$ which is proportional to the probability for positron being captured and annihilate in the trap. Another cause of $\mathrm{I}_{2}$ growth is increased density of defects $\left(\mathrm{N}_{+}\right)$. The correlation between the annihilation parameters $I_{1}, \tau_{1}$ and $I_{2}, \tau_{2}$ indicates what changes in both defect density $\left(\mathrm{N}_{+}\right)$and electron density on defect walls $\left(\rho_{\mathrm{Ps}_{\mathrm{s}}}\right)$ result from the restructuring of the polymer chains, in particular, the redistribution of chain's lateral atomic groups which create defect walls.

As for increasing $\rho_{P_{s}}$ (Fig. 2c), it is also stimulated by the restructuring of polymer chains triggered by nanoparticles. 


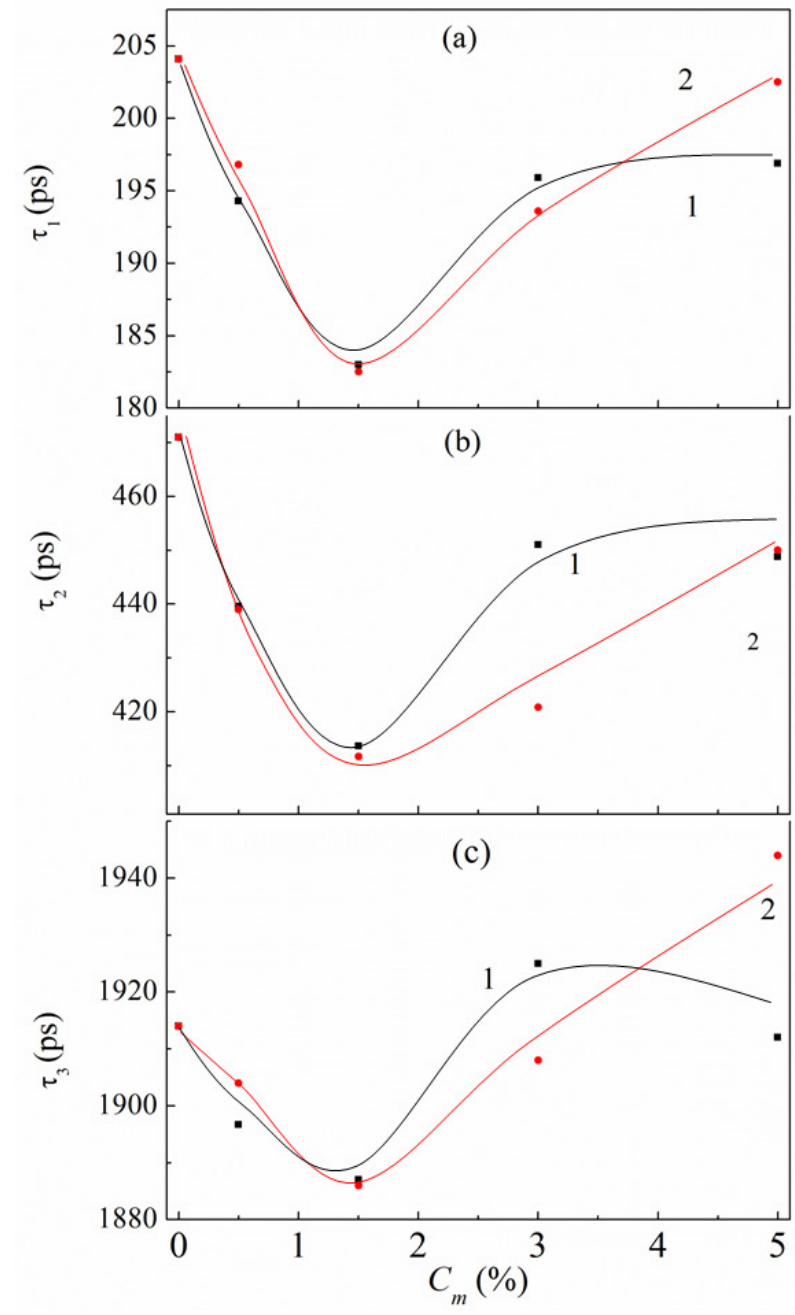

Figure 2. Loading dependences of annihilation lifetimes: a) $\tau_{1}$, b) $\tau_{2}$ and c) $\tau_{3}$ for $\mathrm{TiO}_{2}$ - nanocomposites (the curves "1") and STOnanocomposites (the curves " 2 ")

However, the lack of correlation between the intensity of annihilation of positronium $\left(\mathrm{I}_{3}\right)$ and $\tau_{3}$ indicates that the overall increase of $n_{e}$ and $\rho_{+}$promotes the diffusion of positronium atoms into regions of lower electron density $\left(\rho_{\mathrm{Ps}}<\rho_{+}\right)$. Such regions are predominantly near the surface of nanoparticles. Distribution of charges and the conformation of chains near a particle's surface depend essentially on the particle's density and the number of ASSs on the surface and their chemical activity.

With different activities, ASSs are capable of chemically interacting with unbound polyester chain segments and styrene cross links. In the case of STO particles that have a higher number of ASSs as compared to $\mathrm{TiO}_{2}$, the particles interact more intensively with unbound polymer chain segments for $\mathrm{C}_{\mathrm{m}}>1.5 \%$ [10], and the ASS chemical bond to the chain segments leads to a reduction in $\mathrm{I}_{3}$ (capture and annihilation of orto-positronium). It may be due to a reduction in the number of defects trapping positronium $\left(\mathrm{N}_{\mathrm{Ps}}\right)$. In the case of $\mathrm{TiO}_{2}$ particles that have a less active surface, the hydrogen bonding of ASSs with unbound segments dominates, and changes in their conformation lead to a slight increase of $\left(\mathrm{I}_{3}\right)$ and $\left(\mathrm{N}_{\mathrm{PS}_{\mathrm{S}}}\right)$ at low loadings $\left(\mathrm{C}_{\mathrm{m}}<1.5 \%\right)$ and insignificant declines in both $\mathrm{I}_{3}$ and $\mathrm{N}_{\mathrm{Ps}}$ at higher loadings (Fig. 3c).

It should be noted that the above-described model of the rearrangement of the polymer structure obtained from the results of annihilation studies is consistent with the model based on data from thermal destruction studies. According to the latter [10], the stabilization process of the polymer structure is realized in polyester resin at low loads of $\mathrm{TiO}_{2}$ and STO fillers (namely, when $\mathrm{C}_{\mathrm{m}} \leq 1.5 \%$ ). Stabilization can be imagine as the healing of three dimensional molecular network imperfections due to the binding of dangling bonds of polyester chains and styrene cross links to ASSs. When the structure of the polymer is stabilized, the number of unbound groups is greatly reduced. As load increases, the polymer structure is destroyed due to an increase in the number of short polyester chains, a number of unlinked polyester segments as well as a number of unbound styrene cross-links.

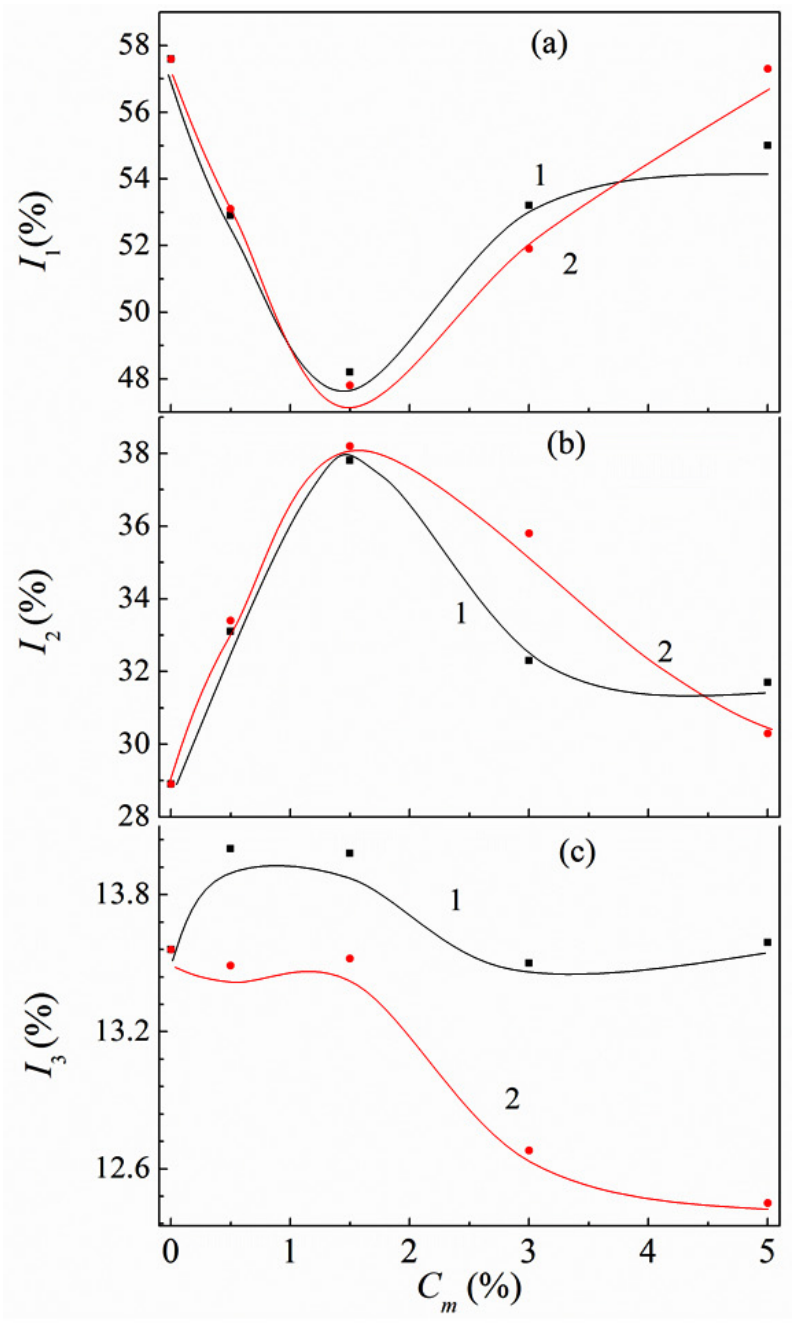

Figure 3. Loading dependences of intensity of lifetime components: a) $\mathrm{I}_{1}$, b) $\mathrm{I}_{2}$, and c) $\mathrm{I}_{3}$ for $\mathrm{TiO}_{2}$-nanocomposites (the curves "1") and STOnanocomposites (the curves "2")

According to the model described above, stabilization of 
the polymeric structure, occurring for $\mathrm{C}_{\mathrm{m}} \leq 1.5 \%$, is accompanied by an increase in electron density - density in the polymer chains $\left(\mathrm{n}_{\mathrm{e}}\right)$ and density on the walls of defects trapping positrons $\left(\rho_{+}\right)$and positronium atoms $\left(\rho_{\mathrm{Ps}_{\mathrm{s}}}\right)$. Increasing $n_{e}$ is due to decrease of the volume occupied by the chains in nanocomposite, and this process manifests itself as decreasing the intensity of the annihilation $\mathrm{I}_{1}$. With respect to the increase of the coefficient $\rho_{+}$, it is most likely to arise from the reduction in the size $\left(\mathrm{R}_{+}\right)$of the corresponding defects. Here, an increase in the intensity of the annihilation $\mathrm{I}_{2}$ may be due to an increase in the number of $\mathrm{N}_{+}$defects. As the load increases above $1.5 \%$, the chain stability is suppressed by their destruction which is reflected in the loading dependencies of inverse parameters $\left(\mathrm{I}_{1}, \tau_{1}\right.$ and $\left.\mathrm{I}_{2}, \tau_{2}\right)$.

The radius $\mathrm{R}_{+}$can be evaluated from the equation [40]

$$
\tau_{2}=0.26\left[1-\frac{R_{+}}{R_{+}+\Delta R}+\frac{1}{2 \pi} \sin \frac{2 \pi R_{+}}{R_{+}+\Delta R}\right]^{-1},
$$

where $\Delta \mathrm{R}=3.823$ is a fitting parameter determined experimentally. In fact, the "(3)" is a well-known Tao-Eldrup equation (see "(4)") there the factor 0.5 is replaced by 0.26 , taking the contribution of positronium annihilation $\left(\tau_{2}\right)$ into account. Numerical calculations show that values of $R_{+}$are ranged from 2.92 to $3.44 \AA$ (see Table 1). It can be seen that $R_{+}$loading relationships are not uniform for both nanocomposites and their minimum values fall for $\mathrm{C}_{\mathrm{m}} \leq 1.5 \%$. This behavior is consistent with the increase of $\rho_{+}$versus $C_{m}$ for $C_{m} \leq 1.5 \%$.

Annihilation of the positronium atoms and their capture in the well of the potential are described in several models. Tao [41] and Eldrup et al. [42] proposed a model in which ortho-positronium atoms are trapped and annihilated in pores with $\mathrm{R}_{\mathrm{PS}_{\mathrm{s}}}$ radii, which are described as infinitely deep, spherical potential wells of size $\mathrm{R}_{\mathrm{Ps}}+\Delta \mathrm{R}$. The Tao-Eldrup model is adequate only when the pores are less than $1 \mathrm{~nm}$ [43] and gives the following relation between the lifetime $\tau_{3}$ of o-Ps and the pore size $\mathrm{R}_{\mathrm{PS}}$ :

$$
\begin{aligned}
& \lambda_{d, T E}^{T}\left(R_{p}\right)=\tau_{3}^{-1}= \\
& =0.5\left[1-\frac{R_{P S}}{R_{P S}+\Delta R}+\frac{1}{2 \pi} \sin \left(\frac{2 \pi R_{P S}}{R_{P S}+\Delta R}\right)\right],
\end{aligned}
$$

where the factor $1 / 2$ characterizes the spin-state-averaged positronium annihilation rate in the vacuum. The empirical parameter $\Delta \mathrm{R}[40,42,44-47]$ was estimated at $1.656 \AA$, by adjusting the experimental values $\tau_{3}$ obtained for material with well-known pore sizes. However, this parameter is the same for all materials and is interpreted as the thickness of the electronic layer located on the wall of the potential well, where the positronium and core electron wave functions overlap.

The volume portion of positronium-trapping pores in a polymer matrix or, by other words, the free-volume portion $f_{V}\left(\right.$ in $\%$ ) can be estimated from the values of $I_{3}$ (in \%) and
$\mathrm{R}_{\mathrm{Ps}}$ (in $\AA$ ) using the relation [40, 42, 44-47]:

$$
f_{\mathrm{V}}=0.0018 \times I_{3} \times\left(\frac{4}{3} \pi R_{P S}^{3}\right)
$$

As an alternative to the Tao-Eldrup model, Ito and coworkers proposed a semi-phenomenological model describing an ortho-positronium annihilation process developed in large spherical cavities. Within this model, although the pore appears again as an infinitely deep well of potential in which the ortho-positronium atom trapped by the wall is no longer represented by the wave function of the standing wave, it behaves more like a quantum particle bouncing back and forth between the barriers energy wells. This ortho-positronium behavior describes a Gaussian wave package and assumes its annihilation in two mechanisms - 1) as an internal annihilation process $3 \gamma$, which occurs in the central pore region of $\mathrm{R}_{\mathrm{Ps}_{\mathrm{s}}}<\mathrm{R}_{\mathrm{A}}$; and 2) as the pick-off annihilation process due to interaction with a core electron within the pore wall that takes place near pore walls for $\mathrm{R}_{\mathrm{P}_{\mathrm{s}}} \geq \mathrm{R}_{\mathrm{A}}$. In other words, when calculating the ortho-positronium annihilation rate in large pores $\left(\lambda_{d}{ }^{T}\right)$ the value of $\lambda_{V}{ }^{T}$ cannot be neglected.

Table 1. Loading dependences for positron- and positronium-trapping defect radii $\left(\mathrm{R}_{+}\right.$and $\left.\mathrm{R}_{\mathrm{Ps}}\right)$

\begin{tabular}{|c|c|c|c|}
\hline Samples & $\mathbf{C}_{\mathbf{m}} \mathbf{( \% )}$ & $\mathbf{R}_{\mathbf{+}}(\mathbf{\AA})$ & $\mathbf{R}_{\mathbf{P s}}(\mathbf{\AA})$ \\
\hline The resin (UPR) & 0.0 & 3.44 & 2.77 \\
\hline \multirow{2}{*}{$\begin{array}{c}\mathrm{TiO}_{2} \\
\text { nanocomposites }\end{array}$} & 0.5 & 3.18 & 2.75 \\
\cline { 2 - 4 } & 1.5 & 2.94 & 2.74 \\
\cline { 2 - 4 } & 3.0 & 3.28 & 2.78 \\
\hline \multirow{3}{*}{$\begin{array}{c}\text { STO } \\
\text { nanocomposites }\end{array}$} & 5.0 & 3.26 & 2.77 \\
\cline { 2 - 4 } & 0.5 & 3.17 & 2.76 \\
\cline { 2 - 4 } & 1.5 & 2.92 & 2.74 \\
\cline { 2 - 4 } & 5.0 & 3.01 & 2.76 \\
\hline
\end{tabular}

Therefore, the following simple relation was deduced in [48] for estimating $\lambda_{\mathrm{d}}{ }^{\mathrm{T}}$ :

$$
\begin{aligned}
& \lambda_{d, \text { Ito }}^{T}\left(R_{P S}\right)= \\
& = \begin{cases}\lambda_{d, T E}^{T}\left(R_{P S}\right)+\lambda_{V}^{T}, & \left(R_{P S}<R_{A}\right) \\
\lambda_{d, T E}^{T}\left(R_{A}\right)+\left[1-\left(\frac{R_{P_{S}}-R_{A}}{R_{P S}+R_{A}}\right)^{b}\right]+\lambda_{V}^{T}, & \left(R_{P S} \geq R_{A}\right)\end{cases}
\end{aligned}
$$

Here $R_{A}$ and $b$ are the empirical parameters equal to: $R_{A}$ $=0.8000 \mathrm{~nm}$, and $\mathrm{b}=0.55, \quad \lambda_{\mathrm{V}}{ }^{\mathrm{T}}=1 / 142 \mathrm{~ns}^{-1}$ (ortho-positronium annihilation rate in vacuum). The parameter $R_{A}+\Delta R$ characterizes the size of a Gaussian wave package or the effective radius of an ortho-positronium atom in a pore. It is seen from "(3)" that $\lambda_{\mathrm{d}, \mathrm{Ito}}^{\mathrm{T}} \rightarrow \lambda_{\mathrm{V}}^{\mathrm{T}}$ when the pore size increases infinitely $\left(\mathrm{R}_{\left.\mathrm{PS}_{\mathrm{S}} \rightarrow \infty\right)}\right.$. 
Gidley and co-authors have proposed another model of interaction between ortho-positronium and polymer material, in order to estimate the pore size of several nanometers [48, 49]. Here again it is assumed that the potential well describing the pores is infinitely deep in energy, but has a rectangular shape of $\mathrm{L}_{1}, \mathrm{~L}_{2}, \mathrm{~L}_{2}$ along the $\mathrm{X}, \mathrm{Y}$ and $\mathrm{Z}$ axes respectively. Thus, the pore size are $\mathrm{L}_{1}-\Delta \mathrm{R}, \mathrm{L}_{2}-\Delta \mathrm{R}$, and $\mathrm{L}_{3}-\Delta \mathrm{R}$. The use of rectangular geometry instead of spherical in model wells avoids troublesome calculations based on Bessel functions. The parameter:

$$
\begin{aligned}
& \lambda_{d, G}^{T}=1 / \tau_{3}= \\
& =0.5\left\{1-\prod_{n=1}^{3}\left[1-\frac{2 \Delta R}{L_{n}+2 \Delta R}+\frac{1}{\pi} \sin \left(\frac{2 \pi \Delta R}{L_{n}+2 \Delta R}\right)\right]\right\} .
\end{aligned}
$$

Table 2 presents the experimental values of lifetime $\tau_{3}$ and related intensity $\mathrm{I}_{3}$ for unfilled resin and its nanocomposites. (Here, the standard deviation values are shown as \pm additions).

Figure 4 shows loading dependences of the normalized free-volume portions, i.e. $\mathrm{f}_{\mathrm{V}}\left(\mathrm{C}_{\mathrm{V}}\right) / \mathrm{f}_{\mathrm{V}}(0)$, calculated for the polyester resin nanocomposites filled with $\mathrm{TiO}_{2}$ (Fig. 4a) and Gidley (3). Here $\mathrm{C}_{\mathrm{V}}$ is the volume loading. According following relationship was obtained for the $\lambda_{\mathrm{d}, \mathrm{G}}^{\mathrm{T}}$ and STO (Fig. 4b) using models of Tao-Eldrup (1), Ito (2),

to these models, positronium-trapping defect radius for the unfilled resin equals to $2.77 \AA, 2.82 \AA$, and $5.53 \AA$, respectively. According to the Tao-Eldrup model, the free-volume portion of unfilled resin equals to $2.17 \%$.

The values of $\mathrm{R}_{\mathrm{PS}_{\mathrm{S}}}$ calculated by using "(4)" are given in Table 1. It can be seen that $R_{P s}$ changes with $C_{m}$ increase are small compared to those obtained for $\mathrm{R}_{+}$. Indeed, the relative reduction of the $R_{P_{s}}$, i.e. $\Delta R_{+} / R_{+}(0)$ is $14-15 \%$ whereas $\Delta \mathrm{R}_{\mathrm{Ps}} / \mathrm{R}_{\mathrm{Ps}}(0)$ is about $1.1 \%$. Such a discrepancy between $\mathrm{R}_{\mathrm{Ps}_{\mathrm{s}}}\left(\mathrm{C}_{\mathrm{m}}\right)$ and $\mathrm{R}_{+}\left(\mathrm{C}_{\mathrm{m}}\right)$ proves that the positron- and positronium-trapping defects are of different nature.

Table 2. Lifetime $\tau_{3}$ and related intensity $\mathrm{I}_{3}$ for unfilled resin and its nanocomposites

\begin{tabular}{|c|c|c|c|}
\hline Samples & $\mathbf{C}_{\mathbf{m}}(\mathbf{\%})$ & $\mathbf{I}_{\mathbf{3}}(\mathbf{\%})$ & $\tau_{3}(\mathbf{p s})$ \\
\hline The resin (UPR) & 0.0 & $13.56( \pm 0.32)$ & $1914.0( \pm 15)$ \\
\hline \multirow{2}{*}{$\begin{array}{c}\text { TiO }_{2} \\
\text { nanocomposites }\end{array}$} & 0.5 & $14.00( \pm 0.27)$ & $1896.7( \pm 5.8)$ \\
\cline { 2 - 4 } & 1.5 & $13.98( \pm 0.36)$ & $1887.0( \pm 11)$ \\
\cline { 2 - 4 } & 3.0 & $13.50( \pm 0.35)$ & $1925.0( \pm 10)$ \\
\hline \multirow{3}{*}{$\begin{array}{c}\text { STO } \\
\text { nanocomposites }\end{array}$} & 5.0 & $13.59( \pm 0.30)$ & $1912.0( \pm 14)$ \\
\cline { 2 - 4 } & 0.5 & $13.49( \pm 0.36)$ & $1904.0( \pm 13)$ \\
\cline { 2 - 4 } & 1.5 & $13.52(0.35)$ & $1886.0(7.9)$ \\
\cline { 2 - 4 } & 5.0 & $12.68( \pm 0.35)$ & $1908.0( \pm 14)$ \\
\hline
\end{tabular}
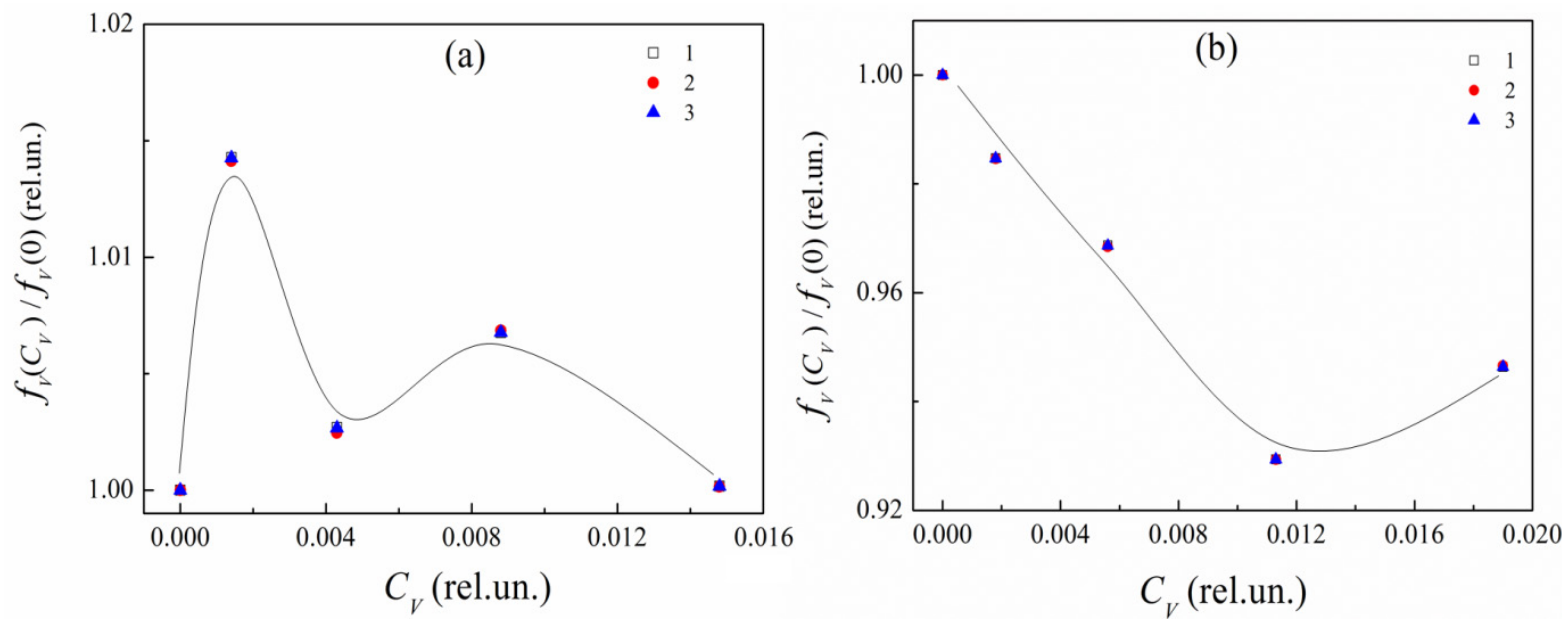

Figure 4. Loading dependences of the normalized free-volume portions calculated for the polyester resin nanocomposites filled with: a) TiO ${ }_{2}$ and b) STO using Tao-Eldrup (black squares), Ito (red circles) and Gidley (blue triangles) models 
In addition, there is no correlation between $\mathrm{I}_{3}\left(\mathrm{C}_{\mathrm{m}}\right)$ and $\mathrm{R}_{+}\left(\mathrm{C}_{\mathrm{m}}\right) . \quad \mathrm{I}_{3}$ is proportional to the number of positronium-trapping defects per unit volume $\left(\mathrm{N}_{\mathrm{Ps}_{\mathrm{S}}}\right)$ and the latter is related to $\mathrm{R}_{\mathrm{Ps}}$ by the equation [50]

$$
v_{P S}=4 \pi D_{P S} R_{P S} N_{P S},
$$

where $v_{P_{s}}$ is positronium trapping rate and $D_{P_{s}}$ is positronium diffusion coefficient. Since for polymers, $D_{\mathrm{Ps}}$ is constant and equals to about $10^{-8} \mathrm{~m}^{2} \mathrm{~s}^{-1}[51,52]$, the absence of correlation may be due to the fact that $v_{\mathrm{Ps}}$ varies with increasing $\mathrm{C}_{\mathrm{m}}$. The relation [53]

$$
v_{P S}=\left(\lambda_{f}-\tau_{2}^{-1}\right)\left(4 I_{3} / 3 I_{10}\right)
$$

where $\lambda_{\mathrm{f}}$ is quasi-free positron annihilation rate, suggests that a discrepancy between $\mathrm{I}_{3}\left(\mathrm{C}_{\mathrm{m}}\right)$ and $v_{\mathrm{Ps}}\left(\mathrm{C}_{\mathrm{m}}\right)$ is due to dependences of both $\mathrm{I}_{10}$ and $1 / \tau_{2}$ versus $\mathrm{C}_{\mathrm{m}}$. The value $1 / \tau_{2}$ is attributed to the contribution of positronium annihilation occurring within positron-trapping defects. Developing that channel of annihilation seems quite likely due to relatively large radius of positron-trapping defects compared to those of positronium - trapping ones, namely $\mathrm{R}_{+}>\mathrm{R}_{\mathrm{Ps}}$.

The models show that both the pure resin and its oxide nanocomposites contain an effective free volume of subnanometer size. It means that the actual size of these volumes is indeed so small that the effect of ortho-positron self-annihilation can be neglected.

As it is seen in Fig. 4, the three models give the identical loading dependences of $\mathrm{f}_{\mathrm{V}}\left(\mathrm{C}_{\mathrm{V}}\right) / \mathrm{f}_{\mathrm{V}}(0)$ for nanocomposites. However, $\mathrm{f}_{\mathrm{V}}\left(\mathrm{C}_{\mathrm{V}}\right)$ - dependences for $\mathrm{TiO}_{2}-$ and STOnanocomposites are different from each other. For the $\mathrm{TiO}_{2}$-nanocomposites $\mathrm{f}_{\mathrm{V}}$ increases slightly for $\mathrm{C}_{\mathrm{V}} \leq 0.002$ $\left(\mathrm{C}_{\mathrm{m}} \leq 0.5 \%\right)$ and then $\mathrm{f}_{\mathrm{V}}$ decreases slowly and non-monotonously when $\mathrm{C}_{V}$ increases further. For the STO-nanocomposites, $f_{V}$ decreases gradually with increasing $\mathrm{C}_{\mathrm{V}}$. The absolute values of the $f_{\mathrm{V}}$ parameter in Tao-Eldrup and Ito models are very close to each other, but in the Gidley model they are higher because of a greater size of pores.

Variations in the free-volume may be due to changes in the number of styrene molecules in the cross-links and the redistribution of positronium-trapping defects due to distortions in the 3D-network molecular structure induced by inner mechanical tensions in the polymer structure. The latter have earlier been revealed by measuring the mechanical parameters of composites [10].

Thus, the nature of the defects that capture the positron and positronium is different. The first are located in a bulk of the 3D-molecular network and the walls of the defects are formed by moieties of polyester chains and styrene cross-links. The second ones are localized near surface of the filling nanoparticles, where walls of the defects are formed by the moieties connected with active surface sites. The molecular conformation of the walls depends on a type of the chemical bonds formed. Positron-trapping defects are located in regions of a greater electron density $\rho_{+}$and they are larger in size than the size of positronium- trapping defects because $R_{+}>R_{P s}$. Positronium atoms annihilate mainly in the regions located near particle's surface where the electron density is smaller namely $\rho_{\mathrm{Ps}_{\mathrm{s}}}<\rho_{+}$.

\subsection{The Supramolecular Structure of the Neat Resin and Its Nanocomposites}

\subsubsection{Calculation of the supramolecular structure parameters}

Besides unavoidable nanosized pores, the supramolecular structure of the polymer matrix may also influence the positron-matrix interaction and result in some features of loading dependences of positron annihilation parameters. In the polyester resin and its random-particulate nanocomposites the units of the supramolecular structure are ordered regions of 3D-network molecular structure (so-called clusters), disordered regions surrounding clusters, and interphase areas surrounding nanoparticles $[38,39]$. It's essentially that all the supramolecular units are the fractal objects [39, $54,55]$.

To predict possible impact of the supramolecular structure on features of the positron annihilation, the fractal approach developed elsewhere [38, 39, 56, 57] have been used to evaluate supramolecular structure parameters, namely relative portions of clusters $\left(\varphi_{\mathrm{CL}}\right)$, disordered areas $\left(\varphi_{D A}\right)$, and interphase areas $\left(\varphi_{\mathrm{IPR}}\right)$. The fractal approach enables the calculation of the special fractal dimensions of the fractal objects by measuring the relationships of the mechanical modules that combine these dimensions with the parameters of the supramolecular structure, molecular characteristics of a host polymer matrix, and geometrical parameters of the filler.

The volume portion $\left(\varphi_{\mathrm{DA}}\right)$ of the disordered (loosely-packed) regions in a nanocomposite can be evaluated as:

$$
C_{V}+\varphi_{\mathrm{IPR}}\left(C_{V}\right)+\varphi_{C L}\left(C_{V}\right)+\varphi_{D A}\left(C_{V}\right)=1,
$$

where $\varphi_{C L}$ is the volume portion of clusters which is the measure of a local order in a polymer [58], $\varphi_{\text {IPR }}$ is the volume portion of the interphase regions surrounding the nanoparticles. The values of $\varphi_{\mathrm{IPR}}$ and $\varphi_{\mathrm{CL}}$ have been evaluated by using the calculation procedures presented in [59] and [53], respectively.

For these procedures, the most essential parameters are the fractal dimension of nanopatricle's surface $\left(d_{n}\right)$ [60] and the fractal dimension $\left(\mathrm{d}_{\mathrm{f}}\right)$ of solid-state polymers and its nanocomposites [61]. $d_{n}$ have been calculated through the particle's radius $R_{f}$ and specific surface area $S_{f}$ of the particles using the formula [59]:

$$
d_{n}=3+\frac{\ln \left(\frac{S_{f}}{420}\right)}{\ln \left(R_{f}\right)}
$$


$\mathrm{d}_{\mathrm{f}}$ have been calculated using the following relation [62]:

$$
d_{f}=2(1+v),
$$

where $v$ is the Poisson's ratio. The dependences of $v$ versus $\mathrm{C}_{\mathrm{m}}$ for the polyester resin nanocomposites filled with $\mathrm{TiO}_{2}$ or STO were obtained from the ultrasonic measurements [10].

Calculations show that supramolecular structure of the UPR with oxide nanoparticles undergoes some variations. Figure 5 shows the loading dependences of the normalized cluster structure parameter, namely $\varphi_{\mathrm{DA}}\left(\mathrm{C}_{\mathrm{V}}\right) / \varphi_{\mathrm{DA}}(0)$. For the unfilled resin $\varphi_{C L}=\varphi_{C L}(0)=35.5 \%, \varphi_{D A}=\varphi_{D A}(0)=$ $64.5 \%$. Since the values of $\varphi_{\text {IPR }}$ and $\mathrm{C}_{\mathrm{V}}\left(\mathrm{C}_{\mathrm{m}}\right)$ grow droningly with increasing $\mathrm{C}_{\mathrm{m}}$ for both the nanocomposites, it's obvious from "(10)" that the dependences of $\varphi_{\mathrm{CL}}$ versus $\mathrm{C}_{\mathrm{V}}$ are always opposite to those of $\varphi_{\mathrm{DA}}$.

For the $\mathrm{TiO}_{2}$-nanocomposites, the cluster structure destructs droningly with increasing $\mathrm{C}_{\mathrm{V}}$, since $\varphi_{\mathrm{DA}}$ increases to $76.1 \%$ at $\mathrm{C}_{\mathrm{V}}=1.5 \%$. For the STO-nanocomposites, the cluster structure varies differently with increasing $\mathrm{C}_{\mathrm{V}}$. At first, $\varphi_{\mathrm{DA}}$ decreases at $\mathrm{C}_{\mathrm{V}} \leq 0.56 \%$ to $\varphi_{\mathrm{DA}}(0.56 \%)=58.2 \%$, then it increases to $64.2 \%$ at $\mathrm{C}_{\mathrm{V}}=1.13 \%$, and it decreases again to $61.7 \%$ at $\mathrm{C}_{\mathrm{V}}=1.9 \%$.

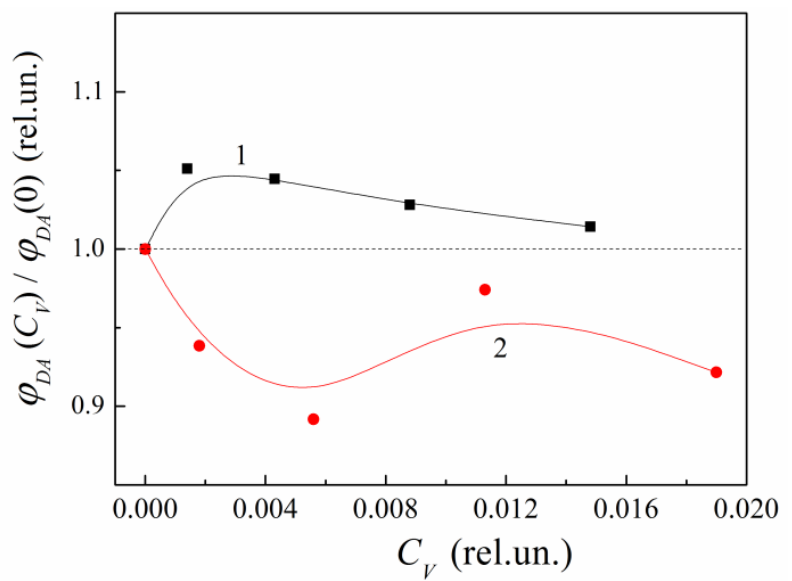

Figure 5. Loading dependences of the normalized portion of disordered areas in the UPR nanocomposites filled with $\mathrm{TiO}_{2}$ (the curve "1") and STO (the curve "2")

\subsubsection{Particle-trapping defects and the supra-molecular structure}

Clusters, disordered areas, and nanoparticles themselves are nanocomposite's structural units where ortho-positronium atoms can penetrate to and annihilate inside. When comparing loading dependences of the fractal parameters (see Fig. 5) and positron-annihilation parameters (see Fig. 4) one can see a correlation between
$\varphi_{\mathrm{DA}}\left(\mathrm{C}_{\mathrm{V}}\right)$ and $\mathrm{f}_{\mathrm{V}}\left(\mathrm{C}_{\mathrm{V}}\right)$ for both nanocomposites. Namely, for $\mathrm{TiO}_{2}$-nanocomposites, non-monotonous increasing of $\mathrm{f}_{\mathrm{V}}$ for $\mathrm{C}_{V} \leq 0.14 \%$ followed by decreasing it for $\mathrm{C}_{V}>0.14 \%$ meets the similar behavior of $\varphi_{\text {DA }}$. In STO-nanocomposites, a qualitative correlation between $\varphi_{\mathrm{DA}}\left(\mathrm{C}_{\mathrm{V}}\right)$ and $\mathrm{f}_{\mathrm{V}}\left(\mathrm{C}_{\mathrm{V}}\right)$ is observed - these parameters decrease as the value $C_{V}$ increases. Correlation indicates that the ortho-positronium atoms diffuse into disordered areas of the supramolecular structure and they annihilate inside. It can therefore be concluded that for both nanocomposites positronium atoms annihilate mainly within the disordered areas of the 3D-polymer network structure.

\subsection{The IR-absorption Data}

IR-absorption spectra for the unfilled resin and its nanocomposites filled with $0.5,1.5,3.0$, and $5.0 \% \mathrm{TiO}_{2}$ and STO are shown in Fig. 6. It's remarkable that the resin filling with either $\mathrm{TiO}_{2}-$ or STO-nanoparticles does not cause disappearance lines or appearance of new ones. On the other hand, by analyzing the spectra closely, it can be seen that the resin absorption lines exhibit slight frequency shifts after filling it with nanoparticles.

Figure 6 shows that the principal effect of resin-doping by nanoparticles, visible in IR spectra, is the non-monotonic relationship of line intensity for both nanocomposites, which is observed with increasing filler loading in the range of $0 \leq \mathrm{C}_{\mathrm{m}} \leq 3.0 \%$. In general, the effects of load on IR line intensities indicates the variability in electronic polarization of interatomic bonds [63] as a result of both dipole moment changes and redistribution of electron density accompanying the change in polymer structure in both nanocomposites.

There is a correlation between $n_{e}$ and intensities $I_{i}(\omega)$ of the lines associated with absorption by dipole groups localized in both polyester chains and styrene cross-links. For example, $-\mathrm{C}=\mathrm{O}$ moieties located in the polyester chains are distinguished by a strong absorption peak at $1738 \mathrm{~cm}^{-1}$ related to their stretching vibration. Two absorption lines located at $\sim 1870 \mathrm{~cm}^{-1}$ and $1945 \mathrm{~cm}^{-1}$ correspond to the overtones of stretching vibration of the $\mathrm{C}=\mathrm{C}$ bonds in the styrene molecules while the wide absorption band in the range of $3012-2785 \mathrm{~cm}^{-1}$ with minimum at $\sim 2951 \mathrm{~cm}^{-1}$ is due to superposition of vibrations of $-\mathrm{CH}$-moieties built in the polyester chains and-OH-groups bounded with the hydrogen bonds.

Loading dependences $\mathrm{I}_{\mathrm{i}}\left(\mathrm{C}_{\mathrm{m}}\right)$ for dipole moieties located both in polyester chains and styrene cross-links are similar. 

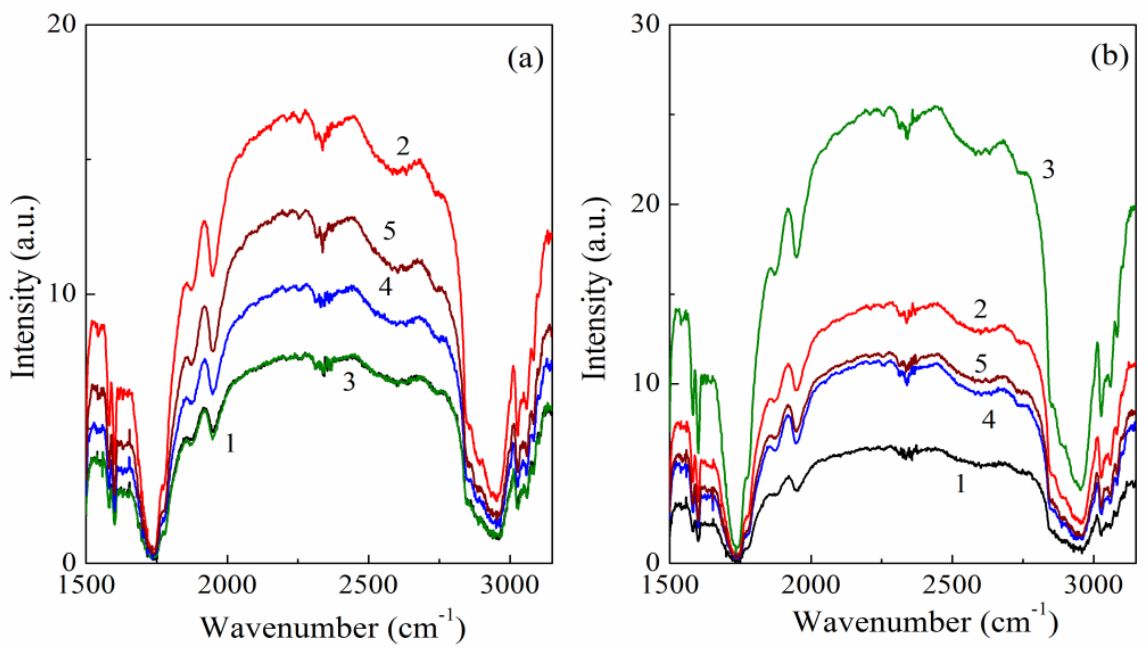

Figure 6. The IR-absorption spectra for the unfilled resin (the curves "1") and its nanocomposites (the curves "2"-“5”) filled with: a) $\mathrm{TiO}_{2}$ and b) $\mathrm{STO}$ at different filler loadings: $0.5 \%$ (the curves " 2 "), $1.5 \%$ (the curves " 3 "), $3.0 \%$ (the curves " 4 "), and $5.0 \%$ (the curves " 5 ")

Dependencies show their non-monotonic increase in the range of $0 \leq \mathrm{C}_{\mathrm{m}} \leq 1.5 \%$ with a maximum at $\mathrm{C}_{\mathrm{m}}=0.5 \%$ for $\mathrm{TiO}_{2}$-nanocomposites and increasing in the range of $0 \leq \mathrm{C}_{\mathrm{m}}$ $\leq 3.0 \%$ with a maximum at $\mathrm{C}_{\mathrm{m}}=1.5 \%$ for STO-nanocomposites. In $\mathrm{TiO}_{2}$-nanocomposites increase intensity when $\mathrm{C}_{\mathrm{m}} \leq 1.5 \%$ coincides with rising ne, but the intensity $\mathrm{I}_{\mathrm{i}}(\omega)$ falls in the region of $1.5 \% \leq \mathrm{C}_{\mathrm{m}} \leq 3.0 \%$ where $n_{e}$ grows further. In STO-nanocomposites, the loading regions in which both $\mathrm{I}_{i}(\omega)$ and $\mathrm{n}_{\mathrm{e}}$ grow are compatible.

Each $\mathrm{i}$-th intensity $\mathrm{I}_{\mathrm{i}}(\omega)$ is proportional to the number of $\mathrm{N}_{\mathrm{i}}$ of absorbing dipole moieties of the i-th type being in an unexcited state and occupying the sample's volume $\mathrm{V}$, and to the squared matrix element $\left|<\mu_{i}>\right|^{2}$ of molecular dipole moment $\mu_{\mathrm{i}}$, according to the expression [64]:

$$
I_{i}(\omega) \propto \frac{N_{i}\left|\left\langle\mu_{i}\right\rangle\right|^{2}}{3 \varepsilon_{0} \hbar V} A\left(\omega_{i}-\omega\right),
$$

where $\varepsilon_{0}$ is the dielectric constant, $\hbar$ is the Planck constant, $\omega_{\mathrm{i}}$ is the frequency of the IR transition, $\mathrm{A}\left(\omega_{\mathrm{i}}-\omega\right)$ is the relaxation parameter characterizing the line width. A quantum-mechanical calculation yields the following expression [65] for the mean dynamic molecular polarizability of the $\mathrm{i}$-th dipole moiety $\left(\alpha_{\mathrm{i}}\right)$ via $\mu_{\mathrm{i}}$ :

$$
\alpha_{i}(\omega)=\frac{2}{3 \hbar} \sum_{n \neq 0} \frac{\omega_{i, n 0} \mid\left\langle\mu_{i}\right\rangle^{2}}{\omega_{i, n 0}^{2}-\omega^{2}},
$$

where $\left|<\mu_{\mathrm{i}, \mathrm{n} 0}>\right|^{2}=<\mu_{\mathrm{i}, \mathrm{n} 0}>\cdot<\mu_{\mathrm{i}, \mathrm{n} 0}>$ and $\hbar \omega_{\mathrm{i}, \mathrm{n} 0}=\mathrm{E}_{\mathrm{i}, \mathrm{n}}{ }^{(0)}-\mathrm{E}_{\mathrm{i}, 0}{ }^{(0)}$. (Here, the subscript " $(0)$ " indicates the ground state of the moiety, the subscript " $n$ " indicates their n-th excited state, and the superscript " 0 " indicates that the energy is evaluated in absence of incident IR-electric field.) Note, that frequency $\omega_{\mathrm{i}}$ measured experimentally should be treated so as to be so close to one of the electronic transition frequencies $\left(\omega_{i, n 0}\right)$ of the moiety that its contribution dominates the frequency dependence of $I_{i}$ as a whole. Taking "(14)" into account, “(13)" can be rewritten as:

$$
I_{i}(\omega) \propto \frac{N_{i} \alpha_{i}(\omega)}{\varepsilon_{0} V} .
$$

Thus, the intensity of the $\mathrm{i}$-th line is proportional to the volume density of dipoles $\left(\mathrm{N}_{\mathrm{i}} / \mathrm{V}\right)$ and to their polarizability $\alpha_{i}$. According to "(14)", the polarizability $\alpha_{i}$ depends on the characteristic frequencies $\omega_{\mathrm{i}, \mathrm{n} 0}$ which are determined by an interaction of the i-th dipole moiety with its neighboring molecular environment. It is the interaction that is represented quantitatively by a set of energy values $\left\{\mathrm{E}_{\mathrm{i}, \mathrm{n}}\right\}$.

When the polymer is filled with nanoparticles, a conformation of molecular environment for the every i-th dipole varies due to binding or bonding chain fragments to ASSs. As a consequence, both the polarizability $\alpha_{i}$ and the related intensity $\mathrm{I}_{\mathrm{i}}$ vary too. It's remarkable that a nature of chemical binding between polymer chains and ASSs has a significant impact on the chain conformations for both nanocomposites. Different surface reactivity of oxides and chemical bonds lead to different conformations of the polymer chains near the filling particles in $\mathrm{TiO}_{2}$ and STO-nanocomposites. This is due to the discrepancy between dependencies of $I_{3}\left(C_{m}\right)$, especially when $\mathrm{C}_{\mathrm{m}} \geq 1.5 \%$ (see Fig. 2c). Therefore it can be assumed that for $\mathrm{TiO}_{2}$-nanocomposites decreasing of intensity $\mathrm{I}_{\mathrm{i}}$ comes from decreasing $\alpha_{\mathrm{i}}$ for moieties surrounding particles.

With filler growth, namely when $\mathrm{C}_{\mathrm{m}} \geq 3.0 \%$, the intensity of the absorption lines increases moderately for $\mathrm{TiO}_{2}$-nanocomposites and slightly for STO-nanocomposites. Under such loadings two processes take place simultaneously, namely, breaking the styrene cross-links and fastening unlinked fragments to ASSs. Both processes have the opposite effect on the polarizability of IR-active dipole moieties, therefore, their absorption intensity versus load is determined by their total effect on the dipole in the composite volume. 


\section{4. $\mathrm{TiO}_{2}-\mathrm{STO}$ Controversy}

It may be suggested that there two main reasons for different behavior of $\mathrm{TiO}_{2}$ and $\mathrm{STO}$ embedded into UPR. The first reason is appearance of so-called interphase regions (IPRs) which surround the nanoparticles embedded in a polymer matrix as a result of peculiarities of particle-resin interaction due to differences in both number and status of ASSs. Analyzing generally accepted chemical structure of the resin and nature of particle's ASSs, one can see that the interaction between macromolecular chains and embedded oxide particles occurs mainly via hydrogen bonding between the surface hydroxyl groups $(-\mathrm{OH})$ of the particles and either the oxygen $(-\mathrm{O}-)$ and methyl groups $\left(\mathrm{CH}_{3}\right)$ in the backbone of polyester chains or methyl groups terminated the free styrene cross-links (see, for example, the details in [66]). Forming IPRs in random-particulate polymer nanocomposites have earlier been shown by various experimental studies [7, 67-69] and theoretical calculations [70-73] and several phenomenological models have been proposed to give qualitative description for the molecular structure of an individual IPR [74-76]. For example, in nanocomposites of polydimethylsiloxane filled with titania nanoparticles (of $20-40 \mathrm{~nm}$ in diameter) formation of IPRs have been suggested to result from strong hydrogen bonding between polymer chains and hydroxyl groups present on the surface of nanoparticle and the thickness of the regions was estimated to 3-5 $\mathrm{nm}$ [69].

The second reason is a formation of the electric double layer due to a difference in the dielectric permittivity between filler and a polymer [77]. Indeed, the intrinsic dielectric permittivity of the 13 -nm-sized $\mathrm{TiO}_{2}$-particles makes about 60 within the frequency range of $10^{3}-10^{5} \mathrm{~Hz}$ [78] exceeds the permittivity of the neat resin which is about 4.5 at $10 \mathrm{kHz}$ [79] whereas the permittivity of STO is close to the latter [80]. It can be suggested that short polar moieties such as unlinked fragment of polyester chains or individual styrene cross-links will contribute into DELs in UPR-based particulate nanocomposites. Details on physical nature of the DEL itself are available in textbooks on electrochemistry $[81,82]$ and in many physical chemistry texts $[83,84]$.

Further details concerning for different behavior of $\mathrm{TiO}_{2}$ and STO nanoparticles in the polyester resin have been extracted from studying mechanical properties, a thermal desorption process can be found elsewhere [85].

\subsection{Remarks on Structure-Property Relations of the Nanocomposites}

As it was noticed in the Introduction, polyester resins as well as epoxy-amine resins derive their physical properties from their complicated, highly cross-linked molecular 3D-network having inhomogeneous (so-called nodular or clusterous) supramolecular architecture at nano-scale, which contains domains with different levels of cross-linking. It's generally accepted, as a result of multiple researches, that thermoset's supramolecular structures are composed of areas of relatively higher cross-linking (or clusters) surrounded by an interstitial phase of relatively lower cross-linking (or disordered areas) [26, 27, 29-31]. These inhomogeneous 3D-network molecular structures drive important physical performance characteristics of thermosets such as modulus, thermal response, solvent/water ingress, and fracture behavior [26, 27 and references herein]. Just as differences in bulk crosslink density and free volume portion lead to different bulk physical and chemical properties, it is reasonable to expect that localized differences in crosslink density, mechanical density, and charge density will lead to local regions with different properties. However, as we know from the literature, no quantitative estimates on supramolecular structure-property relations on random-particulate polyester nanocomposites have been obtained till now. Therefore, we make first careful steps to unveil the issue. An impact of both $\mathrm{TiO}_{2}$ and STO nanoparticles on mechanical, thermal stability and dielectric properties of the unsaturated polyester resin has been experimentally studied by in our recent publication $[85,86]$.

Structural alteration occurring in the nanocomposites at mesoscale, when spatial dimensions of pores capturing positrons and positronium are comparable with size of clusters, can be unveiled analyzing dependences of nanocomposite's dielectric permittivity $\left(\varepsilon_{1}\right)$ versus either volume portion of cluster $\left(\varphi_{\mathrm{CL}}\right)$ or volume portion of disordered areas $\left(\varphi_{\mathrm{DA}}\right)$. Combining correspondent experimental loading dependences of $\varepsilon_{1}$ [86] with calculated loading dependences of $\varphi_{\mathrm{CL}}$ we've replotted loading dependences of dielectric permittivity of both $\mathrm{TiO}_{2^{-}}$and STO-nanocomposites into their dependences versus $\varphi_{C L}$ and $\varphi_{D A}$ on Figs. $7 \mathrm{a}$ and $7 \mathrm{~b}$, respectively.

Here, it should keep on mind that STO-particle occupies an intermedium position (in its values of specific surface area and dielectric permittivity) between titanium dioxide (rutile) and fumed silica, since $\mathrm{S}_{\mathrm{f}}$ increases and $\varepsilon_{1}$ decreases when moving from $\mathrm{TiO}_{2}$ - to $\mathrm{SiO}_{2}$-particles. When comparing the two plots presented on Fig. 7a, one can see three peculiarities occurring in the dielectric reply of a nanocomposite due to that $\mathrm{TiO}_{2}$-filler is replaced by STO- one. The first peculiarity is enhancing the reply and its non-monotonicity at low loadings, when $0.28 \leq \varphi_{\mathrm{CL}} \leq$ 0.36 . In contrast, the non-monotonicity in $\varepsilon_{1}\left(\varphi_{\mathrm{CL}}\right)$ for $\mathrm{TiO}_{2}$-nanocomposites, which is visible at $0.36 \leq \varphi_{\mathrm{CL}} \leq 0.38$, is relatively weak. The second peculiarity is in shifting the reply towards a region of low cluster content. By other words, such a behavior of $\varepsilon_{1}\left(\varphi_{\mathrm{CL}}\right)$-plot reveals that STO-nanoparticles trigger more considerable structural alterations in the resin. These alterations are characterized by disordering 3D-network structure due to disruption of styrene cross-links and to binding polar moieties of the resin's chains to ASSs. It may be suggested that cluster-size distribution takes place and clusters are randomly distributed over resin's bulk varies with increasing loading. Finally, the third peculiarity is lowering a spread of $\varepsilon_{1}$-values. 

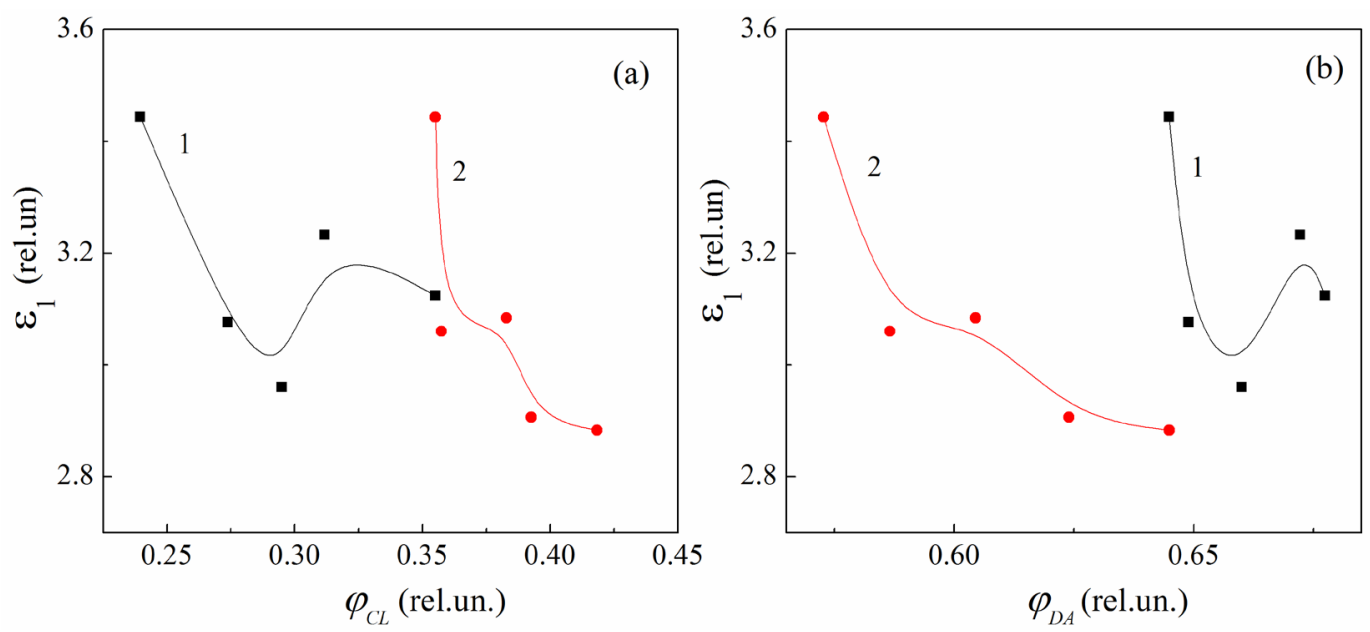

Figure 7. Dielectric permittivity of $\mathrm{TiO}_{2}$ - (the curves "1") and STO - nanocomposites (the curves "2") versus: a) relative volume portions of clusters $\varphi_{\mathrm{CL}}$ and $\mathrm{b}$ ) disordered areas - $\varphi_{\mathrm{DA}}$

A similar behavior is demonstrated by $\varepsilon_{1}$ with increasing volume portion of disordered areas $\left(\varphi_{D A}\right)$, as shown in Fig. $7 \mathrm{~b}$. The $\varepsilon_{1}\left(\varphi_{\mathrm{DA}}\right)$-plot for STO-nanocomposites is shifted towards higher values of $\varphi_{\mathrm{DA}}$ and non-monotonous variations in $\varepsilon_{1}$ are enhanced at low loadings. An essential consequence resulted from the non-monotonicity is that $\varepsilon_{1}$-values measured at different loadings $\left(\mathrm{C}_{\mathrm{m}}\right)$ are proved to be equal. Then, taking into account that both positrons and positronium atoms annihilate mainly within the disordered areas of the nanocomposites, one can conclude that energy of their coulomb interaction with molecular environment $\left(\mathrm{e}^{2} / \varepsilon_{1} \mathrm{r}\right)$ would be the same at different loadings. By other words, at low filler loadings disordered islands may arise in the vicinity of STO-nanoparticles and the annihilation processes within the islands will differ from those within disordered areas remoted from the particles. Both the sources contribute into parameters $\mathrm{I}_{2}, \mathrm{I}_{3}, \tau_{2}$, and $\tau_{3}$ and determine peculiarities of their dependencies on the loading $\left(\mathrm{C}_{\mathrm{m}}\right)$.

\section{Conclusions}

1. The unmonotonic character of the load dependencies of the positron annihilation parameters, such as lifetimes, their intensities, and the free volume portion are related to (i) redistribution of bonded electric charge along both the polyester chains and the styrene cross-links and (ii) rearrangement in spatial configuration of nanosized defects trapping positrons and positronium atoms. Both the effects may be treated as a result of alterations occurring in a 3D-network molecular structure of the resin.

2. Radii of the defects have been calculated by using various theoretical models of positron annihilation. Calculations show there is no correlation between the probability for positrons to be trapped and a number of the defects.

3. For the $\mathrm{TiO}_{2}$-nanocomposites, the free volume portion varies slightly with increasing load, while in the case of the STO-nanocomposites it decreases essentially. The latter effect is likely to result from decreasing a number of styrene molecules making up the cross-links due to higher chemical activity of STO-surface as compared to $\mathrm{TiO}_{2}$-nanoparticles.

4. Regardless of the filler, the loading dependencies for the IR absorption peak intensities are not monotonic for both bending and stretch vibrations of the moieties constituting either the polyester chains or styrene cross-links.

5. The loading effects observed in both the absorption line intensity and positron annihilation parameters indicate that both fillers have a stabilizing effect on the molecular structure of polymer for low loadings (i.e., when $\mathrm{C}_{\mathrm{V}} \leq$ 0.0014 for $\mathrm{TiO}_{2}$ - or $\mathrm{C}_{\mathrm{V}} \leq 0.0056$ for $\mathrm{STO}$-nanocomposites). An underlying mechanism for the stabilizing effect is decreasing a number of unlinked chain's fragments.

6. Fractal analysis shows that filling the polyester resin with oxide nanoparticles results in some alterations in the 3D-network structure, namely in a rearrangement among locally-ordered regions (clusters). Also, a correlation between the loading dependencies of disordered region portion and free volume portion, which have been observed for both the nanocomposites.

7. For both the nanocomposites, different non-monotonous dependences of dielectric permittivity versus the volume portions of clusters or disordered areas unveil differences in mechanisms of oxide-resin interaction and related differences between the nanocomposites in their structural alterations at mesoscale.

\section{Acknowledgements}

The authors thanks to Professor Zbigniew Czapla for his assistance in carrying out the studies. 


\section{REFERENCES}

[1] P. Dittanet, R.A. Pearson. Effect of silica nanoparticle size on toughening mechanisms of filled epoxy, Polymer, Vol.53, 1890-1905, 2012.

[2] J.-S. Jang, B. Bouveret, J. Suhr, R.F. Gibson. Combined numerical/experimental investigation of particle diameter and interphase effects on coefficient of thermal expansion and young's modulus of $\mathrm{SiO}_{2}$ /epoxy nanocomposites, Polym. Compos. Vol.33, 1415-1423, 2012.

[3] A. Legrand, C. Soulié-Ziakovic. Silica-Epoxy vitrimer nanocomposites, Macromolecules, Vol.49, No.16, 5893-5902, 2016

[4] E. Lizundia, I. Serna, E. Axpe, J.L. Vilas. Free-volume effects on the thermomechanical performance of epoxy$\mathrm{SiO}_{2}$ nanocomposites, J. Appl. Polym. Sci. Vol.134, No.34, 45216-45224, 2017.

[5] B.M. Gorelov, A.M. Gorb, O.I. Polovina, Z. Czapla, S. Dacko. Studying mechanical, acoustical and dielectric properties of $\mathrm{SiO}_{2}$-filled polyester resin nanocomposites, Funct. Mater. (Ukraine) Vol.19,493-497, 2012.

[6] B.M. Gorelov, A.M. Gorb, O.I. Polovina, S. Dacko, M. Kostrzewa, A. Ingram. Fumed silica concentration effect on structure and dielectric properties of a styrene-cross-linked unsaturated polyester resin, J. Appl. Phys. Vol.112, 094321-1-11, 2012.

[7] P. Klonos, A. Panagopoulou, L. Bokobza, A. Kyritsis, V. Peoglos, P. Pissis. Comparative studies on effects of silica and titania nanoparticles on crystallization and complex segmental dynamics in poly(dimethylsiloxane), Polymer, Vol.51, 5490-5499, 2010.

[8] P. Carballeira, F. Haupert. Toughening effects of titanium dioxide nanoparticles on $\mathrm{TiO}_{2} /$ epoxy resin nanocomposites, Polym. Compos. Vol.31, 1241-1246, 2010.

[9] P. Jyotishkumar, J. Pionteck, P. Moldenaers, S. Thomas, Preparation and properties of $\mathrm{TiO}_{2}$-filled poly(acrylonitrile-butadiene-styrene)/epoxy hybrid composites. J. Appl. Polym. Sci. Vol.127, 3159-3168, 2013.

[10] M. R. Ambika, N. Nagaiah, S. K. Suman. Role of bismuth oxide as a reinforcer on gamma shielding ability of unsaturated polyester based polymer composites, J. Appl. Polym. Sci. Vol.134, No.13, 44657-44663, 2017.

[11] M. Rubinstein, R.H. Colby. Polymer Physics, Oxford University Press, New York, 2003.

[12] X. Bai, X. He, J. Zhang, X. Zhu, H. Zhang, R. Cheng, B. Liu. Improvement of interfacial interaction, dispersion, and properties of chlorosulfonated polyethylene $/ \mathrm{SiO}_{2}$ nanocomposites using $\mathrm{CSPE}-\mathrm{g}-\mathrm{SiO}_{2}$ nanoparticles synthesized under ultrasonics, Polym. Compos. Vol.33, 940-950, 2012.

[13] R. Jeziórska, B. Świerz-Motysia, M. Zielecka, A. Szadkowska, M. Studziński. Structure and mechanical properties of low-density polyethylene/spherical silica nanocomposites prepared by melt mixing: The joint action of silica's size, functionality, and compatibilizer, J. Appl. Polym. Sci. Vol.125, 4326-4337, 2012.

[14] P. Khodaparast, Z. Ounaies, On the impact of functionalization and thermal treatment on dielectric behavior of low content $\mathrm{TiO}_{2}$ PVDF nanocomposites, IEEE Trans. Dielectr. Electr. Insul. 20, 166-167, 2013.

[15] Y. Lou, M. Liu, X. Miao, L. Zhang, X. Wang. Improvement of the mechanical properties of nano- $\mathrm{TiO}_{2} /$ poly(vinyl alcohol) composites by enhanced interaction between nanofiller and matrix, Polym. Compos. Vol.31 (2010) 1184-1193.

[16] J. Yu, R. Huo, Ch. Wu, X. Wu, G. Wang, P. Jiang. Influence of interface structure on dielectric properties of epoxy/alumina nanocomposites, Macromol. Res. Vol.20, 816-826, 2012

[17] D. Pitsa, M.G. Danikas. Interfaces features in polymer nanocomposites: a review of proposed models, NANO: Brief Rep. Rev. Vol.6, 497-508, 2011.

[18] J.L. Racich, J.A. Koutsky. Nodular structure in epoxy resins, J. Appl. Polym. Sci. Vol.20, No.8, 2111-2129, 1976.

[19] P.J. Aspbury, W. C. Wake. The supermolecular structures found in cured epoxy resins, Polym. Int. Vol.11, No.1, 17-27, 1979.

[20] J.S. Mijovic, J.A. Koutsky. The effect of postcure time on the fracture properties and nodular morphology of an epoxy resin, J. Appl. Polym. Sci. Vol.23, No.4, 1037-1042, 1979.

[21] J.S. Mijovic, J.A. Koutsky. Correlation between nodular morphology and fracture properties of cured epoxy resins, Polymer, Vol.20, No.9, 1095-1107, 1979.

[22] R. Matyi, D. Uhlmann, J.A. Koutsky. Structure of glassy polymers. VII. Small-angle X-ray scattering from epoxy resins, J. Polym. Sci.: Polym. Phys. Ed. Vol.18, No.5, 1053-1063, 1980.

[23] H. Kishi, T. Naitou, S. Matsuda, A. Murakami, Y. Muraji, Y. Nakagawa. Mechanical properties and inhomogeneous nanostructures of dicyandiamide-cured epoxy resins, J. Polym. Sci. B: Polym. Phys. Vol.45, No.12, 1425-1434, 2007.

[24] C.N. Bowman, A.L. Carver, S.N. Kennett, M.M. Williams, N.A. Peppas. Polymers for information storage systems III. Crosslinked structure of polydimethacrylates, Polymer, Vol.31, No.1, 135-139, 1990.

[25] L. Rey, J. Duchet, J. Galy, H. Sautereau, D. Vouagner, L. Carrion. Structural heterogeneities and mechanical properties of vinyl/dimethacrylate networks synthesized by thermal free radical polymerization, Polymer, Vol.43, No.16, 4375-4384, 2002.

[26] C. Sahagun, S. Morgan. Thermal control of nanostructure and molecular network development in epoxy-amine thermosets, ACS Appl. Mater. Interfaces, Vol.4, No.2, 564-572, 2012.

[27] C.M. Sahagun, K.M. Knauer, S.E. Morgan. Molecular network development and evolution of nanoscale morphology in an epoxy-amine thermoset polymer, J. Appl. Polym. Sci. Vol.126, No.4, 1394-1405, 2012.

[28] D. Haba, J. Kaufmann, A.J. Brunner, K. Resch, C. Teichert. Observation of elastic modulus inhomogeneities in thermosetting epoxies using AFM and discerning facts and artifacts, Polymer, Vol.55, No.16, 4032-4040, 2014

[29] S. Morsch, Y. Liu, St.B. Lyon, S.R. Gibbon. Insights into 
epoxy network nanostructural heterogeneity using AFM-IR, ACS Appl. Mater. Interfaces, Vol.8, No.1, 959-966, 2016.

[30] S. Morsch, Y. Liu, P. Greensmith, St.B. Lyon, S.R. Gibbon. Molecularly controlled epoxy network nanostructures, Polymer, Vol.108, 146-153, 2017.

[31] S. Seiffert, J. Sprakel. Physical chemistry of supramolecular polymer networks, Chem. Soc. Rev. Vol.41, 909-930, 2012.

[32] Z.D. Bharatkumar. Use of non-traditional fillers to reduce flammability of polyester resin composites. Polimeri Vol.30, No.1, 10-17, 2009.

[33] S.J. Evans, P.J. Haines, G.A. Skinner. The effects of structure on the thermal degradation of polyester resins, Thermochimica Acta Vol.278, 77-89, 1996.

[34] V.M. Gun'ko, V.I. Zarko, B.A. Chuikov, V.V. Dudnik, Yu.G. Ptushinskii, E.F. Voronin, E.M. Pakhlov, A.A. Chuiko. Temperature-programmed desorption of water from fumed silica, titania, silica/titania, and silica/alumina, Int. J. Mass Spectrom. Ion Processes, Vol.172, 161-179, 1998.

[35] V.M. Gunko, J.P. Blitz, K. Gude, V.I. Zarko, E.V. Goncharuk, Y.M. Nychiporuk, R. Leboda, J. Skubiszewska-Zięba, V.D. Osovskii, Y.G. Ptushinskii, O.A. Mishchuk, S.V. Pakhovchishin, P.P. Gorbik. Surface structure properties of mixed fume oxides, J. Colloid Interface Sci. Vol.314, 119-130, 2007.

[36] S.J. Gregg, K.S.W. Sing. Adsorption, Surface Area and Porosity, Academic Press, NY: London, 1982.

[37] J. Kansy. Microcomputer program for analysis of positron annihilation lifetime spectra, Nucl. Instrum. Methods. Vol.A374, 235-244, 1996.

[38] G.V. Kozlov, Yu.G. Yanovskii, G.E. Zaikov. Structure and Properties of Particulate-Filled Polymer Composites: The Fractal Analysis, Nova Science Publishers, Inc.: New York, 2010.

[39] G.V. Kozlov, G.E. Zaikov. Structure and Properties of Particulate-Filled Polymer Nanocomposites, Lambert Academic Publishing: Saarbrucken, 2012.

[40] Y.C. Jean. Positron annihilation spectroscopy for chemical analysis: A novel probe for microstructural analysis of polymers, Microchem. J. Vol.42, 72-102, 1990.

[41] S.J. Tao. Positronium Annihilation in Molecular Substances, J. Chem. Phys. Vol.56, 5499-5510, 1972.

[42] M. Eldrup, D. Lightbody, J.N. Sherwood. The temperature dependence of positron lifetimes in solid pivalic acid, Chem. Phys. Vol.63, 51-58, 1981.

[43] K. Ito, H. Nakanishi, Y. Ujihira. Extension of the equation for the annihilation lifetime of ortho-positronium at a cavity lager than $1 \mathrm{~nm}$ in radius, J. Phys. Chem. B. Vol.103, 4555-4558, 1999.

[44] Y.Y. Wang, H. Nakanishi, Y.C. Jean, T.C. Sandreczki. Positron annihilation in amine-cured epoxy polymers-pressure dependence, J. Polym. Sci. B: Polym. Phys. Vol.28, 1431-1441, 1990.

[45] C. Ranganathaiah, G.N. Kumaraswamy. New method of determining miscibility in binary polymer blends through hydrodynamic interaction: The free volume approach, J. Appl. Polym. Sci. Vol.111, 577-588, 2009.

[46] J.M. Raj, C. Ranganathaiah. A new method of stabilization and characterization of the interface in binary polymer blends by irradiation: A positron annihilation study, J. Polym. Sci. B: Polym. Phys. Vol.47, No.6, 619-632, 2009.

[47] P. Ramya, C. Ranganathaiah. A New insight into interface widths in binary polymer blends based on ortho-positronium lifetime studies, J. Appl. Polymer Sci. Vol.127, No.1, 190-199, 2013.

[48] D.W. Gidley, W.E. Frieze, T.L. Dull, J.N. Sun, A.F. Yee, C.V. Nguyen, D.Y. Yoon. Determination of pore-size distribution in low-dielectric thin films, Appl. Phys. Lett. Vol.76, 1282-1284, 2000.

[49] D.W. Gidley, W.E. Frieze, T.L. Dull, A.F. Yee, E.T. Rian, H.M. Ho. Positronium annihilation in mesoporous thin film, Phys. Rev. B Vol.60, R5157-R5160, 1999.

[50] G.G. Aleksanyan, A.A. Berlin, A.V. Goldanskyi, N.S. Grineva, V.A. Onistchuk, V.P. Shantorovich. Issledovanie metodom annigilyatsii positronov vliyaniya otzhigai plasticheskoi deformatsii na mikrostructuru poliarilata, Chem. Phys. Vol.9, 1225-1234, 1986. [In Russian]

[51] V.P. Shantorovich, O.E. Mogensen, V.J. Goldanski. Positronium quenching in liquid and solid octanol and benzene, Phys. Lett. A Vol.31, 485-487, 1970.

[52] M. Eldrup, A. Vehanen, P.J. Schultz, K.G. Lynn. Positronium Formation and Diffusion in a Molecular Solid Studied with Variable-Energy Positrons, Phys. Rev. Lett. Vol.51, 2007-2010, 1983.

[53] V.P. Shantorovich, Yu.P. Yampol'skii, I.V. Kevdina, Z.K. Azamatova, V.S. Khotimskii. Examination of free volume elements in polymeric systems by positron annihilation spectroscopy, High-molecular Compainds, Ser.A Vol.39, 445-450, 1977. [In Russian]

[54] B.B. Mandelbrot. The Fractal Geometry of Nature, W.H. Freeman \& Company: San-Francisco, 1982.

[55] J. Feder. Fractals, Springer, 1988.

[56] G.V. Kozlov, G.E. Zaikov. Structure of the Polymer Amorphous State, Brill Academic Publishers, UtrechtBoston, 2004.

[57] M. Vikas. Modeling and Prediction of Polymer Nanocomposite Properties, Wiley-VCH Verlag \& Co, 2013.

[58] G.V. Kozlov, V.U. Novikov. Sinergetika i fraktal'nyi analiz schitykh polimerov, Klassika, Moskwa, 1998.

[59] A. Malamatov, G. Kozlov, M. Mikitaev. Reinforcement mechanisms in polymer nanocomposites, Mendeleev Russian Chemical Engineering University, Moskwa, 2006. [in Russian]

[60] H.G.E. Hentschel, J.M. Deutch. Flory-type approximation for the fractal dimension of cluster-cluster aggregates, Phys. Rev. A Vol.29, 1609-1611, 1986.

[61] P.Penczek, P. Czub, J. Pielichowski. Unsaturated Polyester Resins: Chemistry and Technology. In: Crosslinking in Materials Science. Advances in Polymer Science, Vol 184. 
Springer, Berlin, Heidelberg, 2005.

[62] A. Balankin, A.L. Bugrimov, G.V. Kozlov, A.K. Mikitaev, D.S. Sanditov. The fractal structure and the physical-mechanical properties of amorphous glass-like polymers, Rep. Russia Acad. Sci. Vol.326, 463-466, 1992. [in Russian]

[63] K.-Chi. Kao. Electric Polarization and Relaxation, In: K.-Chi. Kao, Dielectric phenomena in solids, Amsterdam, Boston: Academic Press, 2004, pp 41-114 (Chapter 2).

[64] R. Loudon. The quantum theory of light, Clarendon Press, Oxford University Press, 2000.

[65] P. Atkins, R. Friedman. Molecular Quantum Mechanics, fifth ed., Oxford University Press Inc., New York, 2005.

[66] M.O.W. Richardson. Polymer Engineering Composites, Applied Science Publishers LTD, London, 1977.

[67] S.E. Harton, S.K. Kumar, H. Yang, T. Koga, K. Hicks, H.K. Lee, J. Mijovic, M. Liu, R.S. Vallery, D.W. Gidley. Immobilized polymer layers on spherical nanoparticles, Macromolecules Vol.43, No.7, 3415-3421, 2010.

[68] Y. Termonia. Chain confinement in polymer nanocomposites and its effect on polymer bulk properties, $\mathrm{J}$. Polym. Sci. B Vol.48, No.6, 687-692, 2010.

[69] P. Klonos, C. Pandis, S. Kripotou, A. Kyritsis, P. Pissis. Interfacial effects in polymer nanocomposites studied by dielectric and thermal techniques, IEEE Trans. Diel. Elect. Insul. Vol.19, No.4, 1283-1290, 2012.

[70] G.M. Odegard, T.C. Clancy, T.S. Gates. Modeling of the mechanical properties of nanoparticle/polymer composites, Polymer Vol.46, 553-562, 2005.

[71] T.V.M. Ndoro, E. Voyiatzis, A. Ghanbari, D.N. Theodorou, M.C. Böhm, F. Müller-Plathe. Interface of grafted and ungrafted silica nanoparticles with a polystyrene matrix: Atomistic molecular dynamics simulations, Macromolecules Vol.44, No.7, 2316-2327, 2011.

[72] T.V.M. Ndoro, M.C. Böhm, F. Müller-Plathe. Interface and interphase dynamics of polystyrene chains near grafted and ungrafted silica nanoparticles, Macromolecules Vol.45, No.1, 171-179, 2012.

[73] A. Ghanbari, T.V.M. Ndoro, F. Leroy, M. Rahimi, M.C. Böhm, F. Müller-Plathe. Interphase structure in silicapolystyrene nanocomposites: a coarse-grained molecular dynamics study, Macromolecules Vol.45, No.1, 572-584, 2012.

[74] G. Tsagaropoulos, A. Eisenberg. Dynamic mechanical study of the factors affecting the two glass transition behavior of filled polymers. Similarities and differences with random ionomers, Macromolecules Vol.28, No.18, 6067-6077, 1995.

[75] H. Zhang, A.A. Hassanali, Y.K. Shin, C. Knight, S.J. Singer. The water-amorphous silica interface: analysis of the Stern layer and surface conduction, J. Chem. Phys. Vol.134, No.2, $024705,2011$.

[76] T. Tanaka, M. Kozako, N. Fuse, Y. Ohki. Proposal of a multi-core model for polymer nanocomposite dielectrics, IEEE Trans. Diel. Elect. Insul. Vol.12, No.4, 669-681, 2005.

[77] T.J. Lewis. Interfaces are the dominant feature of dielectrics at the nanometric level, IEEE Trans. Diel. Elect. Insul. Vol.11,No.5, 739-753, 2004.

[78] S. Sagadevan. Synthesis and electrical properties of $\mathrm{TiO}_{2}$ nanoparticles using a wet chemical technique, American Journal of Nanoscience and Nanotechnology Vol.1, No.1, 27-30, 2013.

[79] R.J.A. Shalash, M.S. AbdulWahab, A.N.H. Al-Ajili. Dielectric properties of thermally-aged unsaturated polyester resin, Polymer Degradation and Stability, Vol. 24, No.4, 373-380, 1989.

[80] V.I. Zarko, A.V. Gette, G.M. Kozub, P.V. Sushko, A.A. Chuiko. Structural and electrophysical characteristics of titanium dioxide silicon, Inorg. Mater. 19, 239-241, 1983. [in Russian]

[81] K.B. Oldham, J.C. Myland. Fundamentals of Electrochemical Science, Academic Press, San Diego, 1993.

[82] A.J. Bard, L.R. Faulkner. Electrochemical Methods, second ed., Wiley, New York, 2000, (Chapter 13).

[83] A. Sridharan, P.V. Satyamurty. Potential-distance relationships of clay-water systems considering the Stern theory, Clays and Clay Minerals Vol. 44, No. 4, 479-484, 1996.

[84] K.B. Oldham. The water-amorphous silica interface: analysis of the Stern layer and surface conduction, J. Electroanalytical Chemistry, Vol.613, No.4, 131-138, 2008.

[85] B. Gorelov, A. Gorb, O. Korotchenkov, A. Nadtochiy, O. Polovina, N. Sigareva. Impact of titanium and silica/titanium fumed oxide nanofillers on the elastic properties and thermal decomposition of a polyester resin, Appl. Polymer Sci. Vol.132, No.22, 1-12, 2015.

[86] B.M. Gorelov, A.M. Gorb, O.I. Polovina, S. Wacke, Z. Czapla, M. Kostrzewa, A. Ingram. Filler's impact on structure and physical properties in polyester resin-oxide nanocomposites, Adsorption Science \& Technology Vol.36, No.1-2, 1-30, 2017. 